\title{
MOBILIZAÇÃO DE TÓRIO EM ÁGUAS SUBTERRÂNEAS DE ÁGUAS DA PRATA, ESTADO DE SÃO PAULO
}

\author{
ÉRICA MARTINI TONETTO' \& DANIEL MARCOS BONOTTO ${ }^{2}$
}

\begin{abstract}
THORIUM MOBILIZATION IN GROUNDWATERS FROM ÁGUAS DA PRATA, SÃO PAULO STATE The paper describes and discusses results of the determination, by alpha spectrometry, of the natural thorium isotopes in groundwaters associated with different rock types in Águas da Prata spa, state of São Paulo. The dissolved Thorium is relatively low $(0.003$ to $1.72 \mu \mathrm{g} . \mathrm{L}^{-1}$ for ${ }^{232} \mathrm{Th}$ ), while the ${ }^{228} \mathrm{Th} /{ }^{232} \mathrm{Th}$ isotopic ratios for dissolved thorium were higher than unity (1.8 to 34$)$. The thorium concentration in suspended solids of these waters ranged between 183 up and $3445 \mu \mathrm{g} . \mathrm{g}^{-1}$ and indicates that significant thorium transport occurs under this condition. The obtained results allowed to calculate the factor for preferential mobilization of thorium in particulate matter relative to the liquid phase, an important parameter for understanding the geochemical behaviour of this element in hydrosphere.
\end{abstract}

Keywords: Thorium isotopes, groundwater, Águas da Prata.

\begin{abstract}
RESUMO Foram determinados, por espectrometria alfa, os isótopos naturais de tório presentes em águas subterrâneas associadas com diferentes litologias na estância hidromineral de Águas da Prata, Estado de São Paulo. Os teores de tório dissolvido foram baixos $\left(0,003\right.$ a $\left.1,72 \mu \mathrm{g} . \mathrm{L}^{-1} \mathrm{de}{ }^{232} \mathrm{Th}\right)$, enquanto que as razões isotópicas ${ }^{228} \mathrm{Th} /{ }^{232} \mathrm{Th}$ de tório dissolvido excederam a unidade ( 1,8 a 34). A concentração de tório de sólidos em suspensão nestas águas variam entre 183 e $3445 \mu \mathrm{g} . \mathrm{g}$ ' e revelam a possibilidade de transporte significativo de Th sob esta forma. Os resultados obtidos permitiram calcular o fator de mobilização preferencial de tório no material particulado em relação à fase líquida, parâmetro importante para a compreensão do comportamento geoquímico deste elemento na hidrosfera.
\end{abstract}

Palavras-chaves: isótopos de tório, água subterrânea, Águas da Prata,

INTRODUÇÃO O tório é um elemento instável, sendo o ${ }^{232}$ Th o precursor da série natural de decaimento $4 \mathrm{n}$ (série do tório), que origina o ${ }^{208} \mathrm{~Pb}$ após 12 transformações (7 do tipo alfa e 5 do tipo beta), ocorrendo na mesma série outro isótopo de tório, $\mathrm{o}^{228} \mathrm{Th}$ (meia-vida de 1,9 anos). O tório também está presente como ${ }^{230} \mathrm{Th} \mathrm{e}^{234} \mathrm{Th}$ na série natural de decaimento $4 \mathrm{n}$ + 2 (série do urânio), como ${ }^{231} \mathrm{Th}$ na série do actínio e como ${ }^{229} \mathrm{Th}$ na série $4 \mathrm{n}+1$ (série do neptúnio).

Este elemento é cerca de três a quatro vezes mais abundante na crosta terrestre do que o urânio, por ser menos sujeito à mobilização no ambiente supérgeno (Gabelman 1977). Ocorre predominantemente como um cátion tetravalente, sendo um constituinte traço em fosfatos, óxidos simples e múltiplos e silicatos, bem como um elemento principal na torianita $\left(\mathrm{ThO}_{2}\right)$ e torita $\left(\mathrm{ThSiO}_{4}\right)$, dentre outros minerais (Ivanovich \& Harmon 1982).

Uma vez que sua presença é verificada em minerais de difícil dissolução, em geral, o tório tem sido considerado bastante insolúvel em água, entretanto, a formação de complexos inorgânicos com os íons $\mathrm{Cl}^{-}, \mathrm{NO}_{3}^{-} \mathrm{H}_{3} \mathrm{PO}_{4}^{0}, \mathrm{H}_{2} \mathrm{PO}_{4} ; \mathrm{SO}_{4}^{2}, \mathrm{~F}^{-}$, $\mathrm{OH}^{-}$e $\mathrm{HPO}_{4}{ }^{2-}$ e orgânicos como oxalatos, citratos e ácido etilenodiamino tetracético (EDTA), contribui para que sua mobilidade seja favorecida no ambiente hídrico. Outros fatores como o pH e a intensidade iônica (Langmuir \& Herman 1980) também podem favorecer a solubilização e mobilização do tório nas águas, não podendo ser ignorado que esse elemento também ocorre adsorvido no material particulado em suspensão na água, tanto inorgânico (argilas e colóides) como orgânico (Langmuir \& Herman 1980, Ferronsky \& Polyakov 1982).

As avaliações do comportamento do tório em água têm sido objeto de vários estudos em águas de oceanos (e.g. Moore \& Sackett 1964, Bacon \& Anderson 1982), águas doces de rios (e. g. Anderson et al. 1995) e águas subterrâneas (e.g. Langmuir \& Herman 1980). No Brasil, as pesquisas envolvendo o tema tiveram um bom desenvolvimento a partir do trabalho de Lei (1984), no qual o autor efetuou um estudo sistemático do comportamento do tório em águas subterrâneas e superficiais no Morro do Ferro, uma área mineralizada a tório situada no planalto de Poços de Caldas, há cerca de $60 \mathrm{~km}$ daquela abordada nesta investigação, isto é, Águas da Prata.

$O$ presente trabalho enfoca a caracterização dos isótopos naturais de tório ${ }^{232} \mathrm{Th},{ }^{230} \mathrm{Th}$ e ${ }^{228} \mathrm{Th}$ efetuada para amostras de águas subterrâneas de surgências naturais ou captadas por poços tubulares, na estância hidromineral de Águas da Prata, Estado de São Paulo. A região foi selecionada em virtude de suas particularidades geológicas e por ser uma área na qual já foram desenvolvidos diversos estudos em relação à ocorrência natural de nuclídeos radioativos, tais como urânio (Bonotto 1982) e radônio (Szikszay 1981, Lima 1993). Ademais, possibilita comparações com resultados de estudos prévios realizados no

I - Pós-Graduação em Geociências, Área de Concentração Geociências e Meio Ambiente, UNESP - Universidade Estadual Paulista - Câmpus de Rio Claro, Caixa Postal 178, CEP 13506-900, Rio Claro - SP - Telefone: (019) 526-2802, Fax: (019) 524-9644 - e-mail: etonetto@rc.unesp.br

2 - Departamento de Petrologia e Metalogenia, UNESP - Universidade Estadual Paulista - Câmpus de Rio Claro

Telefone: (019) 526-(0300, Fax: (019) 524-9644 - e-mail: dbonotto@rc.unesp.br 
planalto de Poços de Caldas (Lei 1984, Chapman et al. 1991).

\section{ÁREA DE ESTUDO Localização e aspectos geológicos} O município de Águas da Prata situa-se no Estado de São Paulo, localizando-se, sua sede, a $21^{\circ} 56^{\prime} 04^{\prime \prime}$ de latitude sul e $46^{\circ} 42^{\prime} 39^{\prime \prime}$ de longitude oeste (Fig. 1). O clima da região é tropical de altitude, caracterizado por uma estação fria e seca de abril a setembro (temperatura média de $18^{\circ} \mathrm{C}$ e precipitação entre 15 e $80 \mathrm{~mm} / \mathrm{mês}$ ) e outra quente e úmida - de outubro a março (temperatura média de $26^{\circ} \mathrm{C}$ e a precipitação entre 100 a $255 \mathrm{~mm} / \mathrm{mês}$ ) (Migliorini Jr. et al. 1983, Etchebehere 1990).

O município se localiza próximo à divisa entre os estados de São Paulo e Minas Gerais, estando inserido no contexto geológico do maciço alcalino de Poços de Caldas e dos limites da bacia sedimentar do Paraná. A intrusão alcalina no Planalto de Poços de Caldas estende-se por $800 \mathrm{~km}^{2}$, apresenta conformação apximadamente circular (diâmetro médio de $30 \mathrm{~km}$ ), com altitudes médias de 1200 a $1300 \mathrm{~m}$, ao seu redor aflorando rochas do embasamento cristalino (granitos e gnaisses) (Ulbrich \& Gomes 1981).

Na saída de Águas da Prata para Poços de Caldas, ao longo do vale do Quartel, encontram-se afloramentos de rochas de

$$
47^{\circ} W G
$$

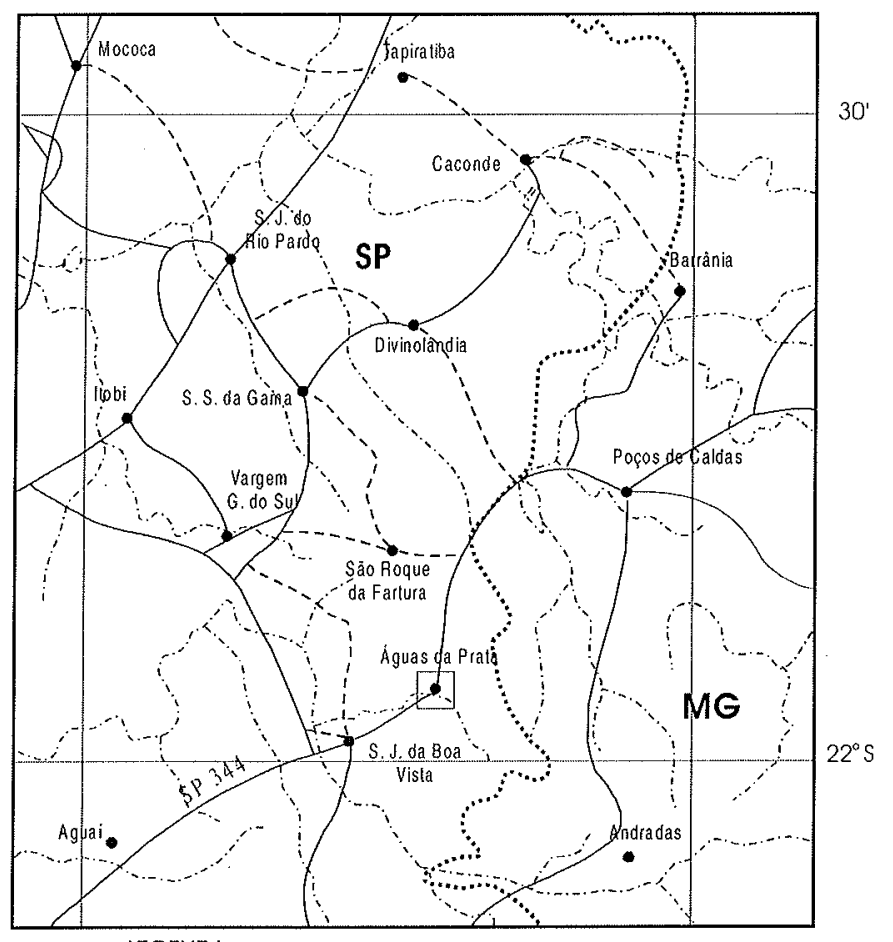

LEGENDA
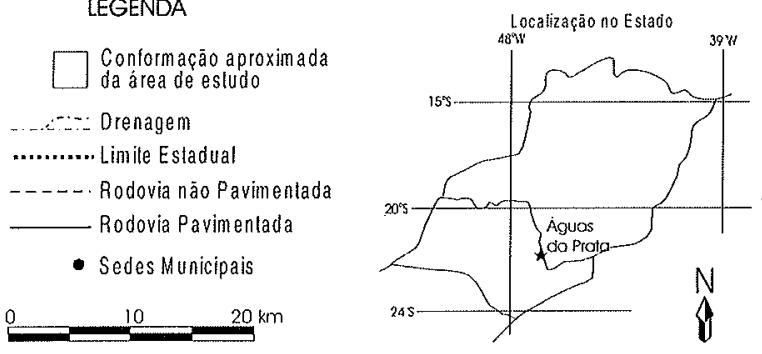

Figura 1 - Mapa de localização da área de estudo com principais vias de acesso. Modificado de Lima (1993). origem vulcânica, brechas e tufos, geralmente associados a arenitos (Szikszay 1981) (Fig. 2). Um pacote com mais de 100 $m$ de espessura dessa rocha clástica ocorre logo na saída do perímetro urbano no vale do Quartel, em cuja base foi identificado um folhelho com numerosas intercalações de leitos arenosos e siltosos concordantes com a estratificação. Em Águas da Prata e arredores também ocorrem arenitos avermelhados pertencentes à Formação Aquidauana, cujas características principais são a granulação variada (fina a média), composição quartzo-feldspática, grãos subarredondados, mal selecionados, com boa esfericidade e estratificação plano-paralela. Ainda como ocorrências sedimentares pode-se acrescentar os alúvios que acompanham a extensão das redes de drenagem como o Ribeirão da Prata e o Ribeirão da Platina (MiglioriniJr. et al. 1983).

Nas rochas sedimentares ocorrem intrusões de diabásio, que aparecem como diques e pequenos sills irregulares aflorando, principalmente, ao norte de Águas da Prata (Ellert 1959). As rochas de origem vulcânica apresentam-se, normalmente, como corpos de pequena extensão (Etchebehere 1990 e Migliorini Jr. et al. 1983). Björnberg (1959) encontrou em brechas e tufos vulcânicos, desde Águas da Prata até Poços de Caldas, fragmentos de diabásio alterado, sienito, quartzito, lava e gnaisses. Na região, o diabásio apresenta-se fissurado e descontínuo, permitindo a surgência das águas de três das fontes amostradas (Szikszay \& Teissedre 1977).

Dentre as rochas alcalinas do maciço de Poços de Caldas, tinguaíto e fonólito são os litotipos predominantes em Águas da Prata a arredores, sendo o primeiro uma rocha compacta cinza escura e esverdeada, cujos constituintes principais são sanidina, anortoclásio, nefelina, egirina e gianetita. Como acessórios ocorrem biotita, apatita, zircão e lamprofilita (Szikszay 1981). Os fonólitos apresentam granulação mais fina, são mais compactos, não porosos e de coloração cinza escura (Barbosa 1979).

FONTES (POÇOS) AMOSTRADAS Uma vez que diferentes rochas são lixiviadas pelas águas subterrâneas estudadas, optou-se pela descrição individual de cada ponto de amostragem, cuja localização está ilustrada na figura 2.

Fonte Villela - surge ao pé de um paredão de cerca de $10 \mathrm{~m}$ de altura, no topo de uma escarpa de arenito bastante silicificado e com dobramentos leves. A água surge por fraturas abertas no sentido vertical e horizontal (Szikszay 1981, Szikszay \& Sampa 1982); a fonte Villela é uma das mais radioativas do Estado de São Paulo relativamente ao teor de radônio dissolvido (Longo 1967).

Fonte Vitória Surge numa baixada em pequena planície aluvionar dominada a noroeste por uma elevação formada por um maciço de diabásio, emergindo suas águas do sopé desse maciço por meio de fissuras. Sua origem parece ser profunda, chegando a água à superfície por meio de circulação ascendente (Mero et al. 1980, Szikszay 1981). Atualmente, sua captação é efetuada por meio de um poço tubular instalado próximo à antiga surgência, prestando-se ao suprimento de água para a população, por intermédio de torneiras bem localizadas.

Fonte Platina Emerge de uma lente de fonólito aflorante, sua água surgindo de fraturas verticais por circulação ascendente. O corpo de fonólito aparece no fundo do vale de um 


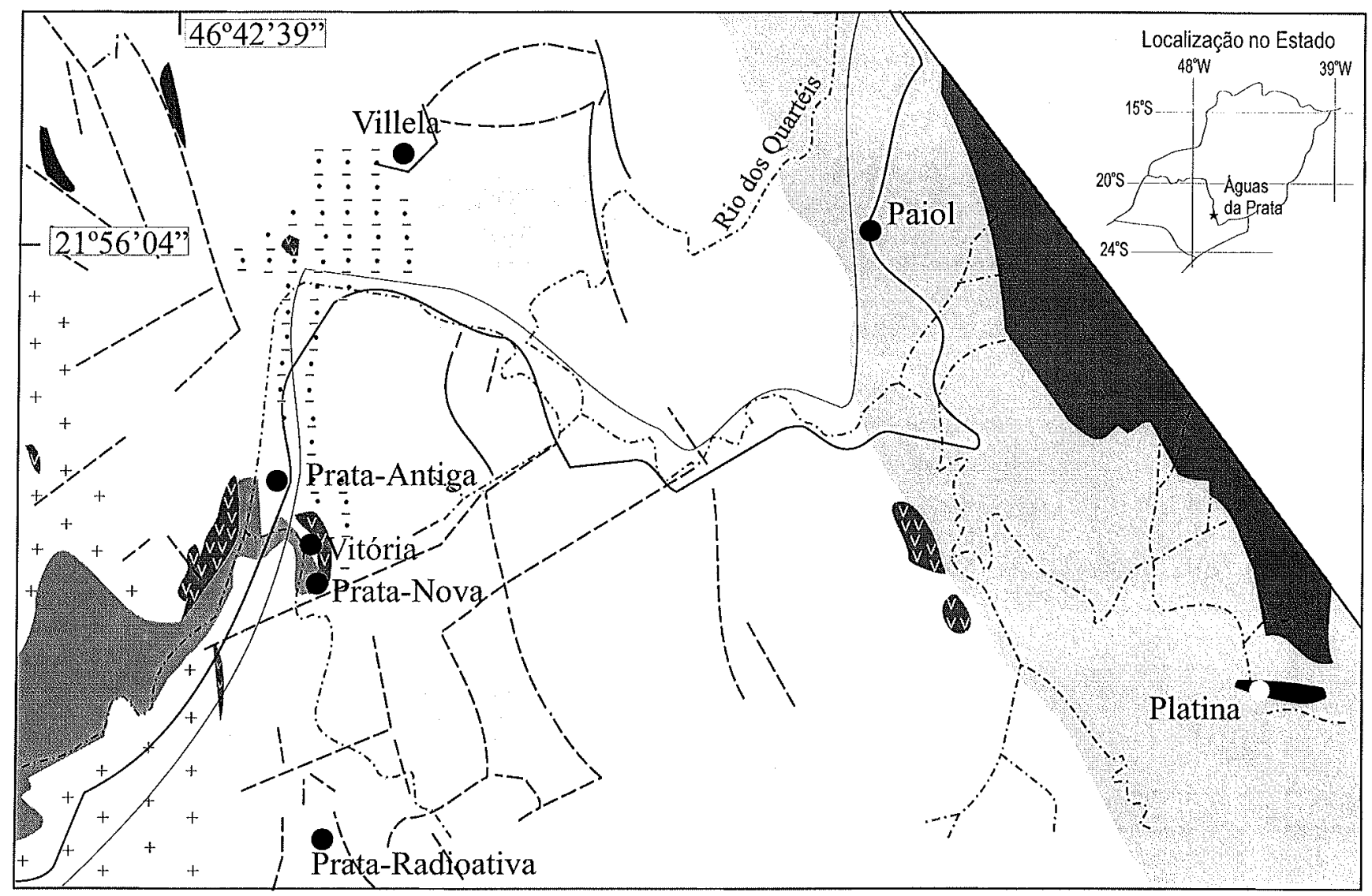

\section{LITOLOGIAS}

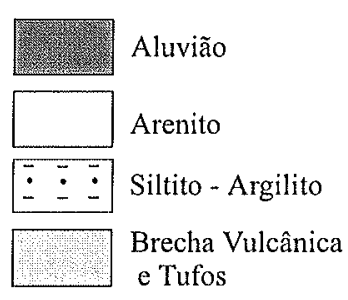

CONVENÇÕES
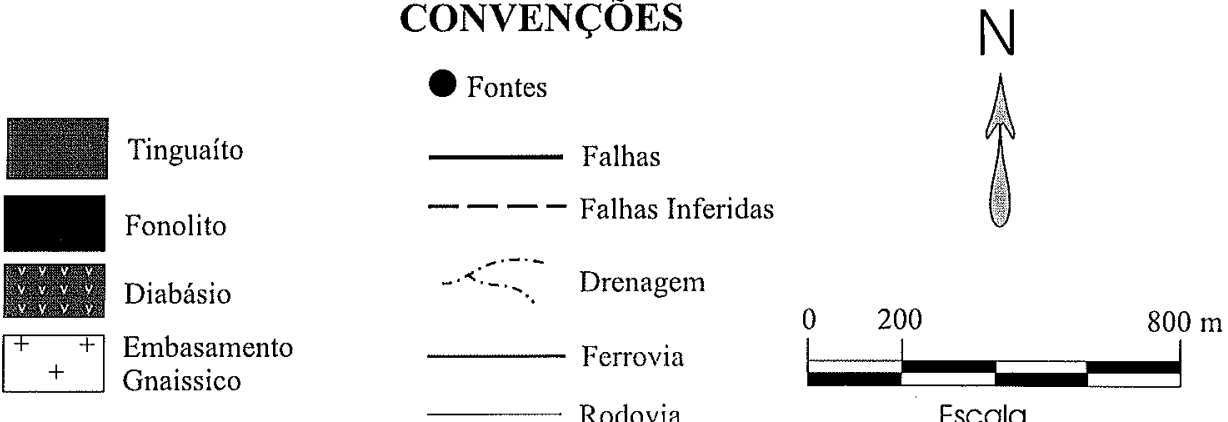

Escala

Figura 2 - Mapa geológico e de localização das fontes amostradas para a execução das análises de tório no município de Águas da Prata, Estado de São Paulo. Modificado de Taltasse \& Bittencourt (1972) (apud Szikszay 1981).

córrego, apresentando extensão restrita e contatos bem definidos (Mero et al. 1980, Szikszay 1981).

Fonte Próx. Platina Apesar de se localizar a $50 \mathrm{~m}$ da Fonte Platina, estas águas percolam somente a cobertura de alteração intempérica do terreno, sendo, portanto, sua surgência distinta daquela da Fonte Platina.

Fonte Prata-Radioativa Localiza-se em local elevado, com a água surgindo das fraturas de arenito silicificado e recristalizado, em contato com siltitos (Szikszay 1981). O corpo de arenito de onde surge é o mesmo descrito para a Fonte Villela (Szikszay \& Sampa 1982).

Fonte Prata-Antiga Foi a primeira captação da cidade, localizando-se à margem direita do Rio do Quartel. Surge de fraturas e fissuras no diabásio, sendo a captação efetuada por meio de uma perfuração no diabásio com profundidade aproximada de $13 \mathrm{~m}$ (Szikszay 1981).

Fonte Prata-Nova É um conjunto de poços cuja profundidade alcança $15,90 \mathrm{~m}$, dos quais $13,20 \mathrm{~m}$ perfuram diabásio e o restante atravessa fonólitos. Estes poços estão escavados numa baixada em pequena planície aluvionar, já citada na descrição da Fonte Vitória, dos quais a água surge jorrante (Szikszay 1981).

Fonte Paiol Sua surgência ocorre em rochas alcalinas do tipo tufos vulcânicos líticos, foiaítos e fonólitos. O exame de 
testemunhos de nove furos efetuados próximos à nascente indica a presença de minerais como ortoclásio, anortoclásio, sanidina, nefelina, egirina, anfibólio sódico, apatita, biotita, sodalita, hauyna, cancrinita, catapleita, gianetita, eudialita, zeólita e zircão (Felicíssimo Jr. 1965).

Fonte Próx. Paiol Situa-se a cerca de $50 \mathrm{~m}$ da Fonte Paiol, suas águas possuindo características químicas distintas daquela por percolarem apenas o manto de intemperismo e surgirem no contato entre o capeamento de solo e o substrato rochoso.

Como se pode notar, as águas das fontes amostradas interagem com substratos distintos (diabásio, arenito, rochas vulcânicas e solos), o que pode refletir de maneira diferente em sua composição química (Szikszay 1981) e, consequentemente, na solubilização e mobilização do tório (Langmuir \& Herman 1980).

PROCEDIMENTOS ANALÍTICOS Uma duplicata de 20 l de água de cada fonte foi coletada para as determinações de Th a partir do método escolhido, quantidade esta necessária, pois o elemento geralmente ocorre em níveis muito baixos requerendo um volume inicial dessa ordem para realizar as medidas.

A extração de tório foi conduzida simultaneamente para as duas alíquotas coletadas; a uma delas adicionou-se $100 \mu \mathrm{l}$ do traçador ${ }^{228} \mathrm{Th}+{ }^{232} \mathrm{U}$ em equilíbrio radioativo (atividade de ${ }^{228} \mathrm{Th}$ igual a 3,39 desintegrações por minuto) agitando-se bem para homogeneização (Bonotto 1990). A seguir, realizou-se a coprecipitação do tório e outros metais pesados com cloreto férrico, procedendo-se, então, a eliminação do ferro adicionado com éter di-isopropílico (Dodson et al. 1936).

A extração prosseguiu com a separação do tório em relação ao urânio, uma vez que $\mathrm{o}^{234} \mathrm{U}$ e $\mathrm{o}^{230} \mathrm{Th}$ da série do urânio possuem valores próximos de energia de emissão alfa, podendo o ${ }^{234} \mathrm{U}$ impedir a obtenção dos dados de ${ }^{230} \mathrm{Th}$. A separação dos isótopos de urânio foi efetuada pela passagem da soluçã̃o com tório (HCl 8M) em resina de troca aniônica Rexyn 201 da Fisher Scientific Company, inserida em coluna de vidro (com volume de $30 \mathrm{ml}$ e torneira na parte inferior para regular o fluxo) preparada com $\mathrm{HCl} 8 \mathrm{M}$. A eluição destes elementos e do ferro foi efetuada utilizando-se $\mathrm{HNO}_{3} 7 \mathrm{M}$.

Foi necessária uma segunda passagem na coluna de resina trocadora de íons, desta vez acidificada com $\mathrm{HNO}_{3} 7 \mathrm{M}$, para separar o tório dos outros elementos presentes na solução. Neste meio os isótopos de tório ficam retidos na resina e são posteriormente eluídos com $\mathrm{HCl} 2 \mathrm{M}$.

Para determinar os isótopos de tório utilizou-se a técnica de espectrometria alfa, em virtude da sua adequação à realização de medidas em amostras com baixa atividade (Ivanovich \& Harmon 1982). Por esta técnica, a partir da amostra de água, prepara-se uma fonte de emissão delgada, plana e uniformemente distribuída em um disco de aço inoxidável (Ivanovich \& Harmon 1982). A seguir, em um espectrômetro alfa, são efetuadas as leituras de energia de emissão, por meio da qual se caracterizam os nuclídeos presentes, já que cada um deles emite partículas alfa com energia bem definida. A leitura do número de contagens de cada nuclídeo emissor alfa permite o cálculo de sua concentração, baseando-se na técnica de diluição isotópica, e de razões de atividade envolvendo pares relacionados de nuclídeos (Bonotto 1986, Tonetto 1996).
Para a obter a fonte de emissão optou-se pelo emprego da técnica de eletrodeposição, utilizando-se um disco de aço inoxidável como cátodo e uma haste de platina como ânodo de acordo com o sistema descrito por Bonotto (1996) e implantado no LABIDRO - Laboratório de Isótopos e Hidroquímica do Departamento de Petrologia e Metalogenia do Instituto de Geociências e Ciências Exatas - UNESP - Rio Claro. Depois de preparado, o disco foi inserido em câmara de vácuo e posicionado a uma distância de poucos milímetros de detector semicondutor de barreira de superfície ligado a um préamplificador.

Dois sistemas espectrométricos foram empregados para a realização das medidas. No primeiro (MCB-1), o detector é polarizado por fonte estabilizada com tensão de $125 \mathrm{~V}$, estando acoplado a um pré-amplificador da ORTEC, Modelo 109 A, o qual por sua vez, está ligado a um amplificador também da Ortec, Modelo 485. No segundo (MCB-2), o detector está polarizado por uma fonte estabilizada à tensão de $50 \mathrm{~V}$, conectado a um pré-amplificador Robotron, Modelo 20042, o qual está ligado a um amplificador da Ortec, Modelo 575-A. Os dois amplificadores, por sua vez, estão conectados a distintas placas da Ortec Modelo 916A, consistindo de conversor analógico digital, microprocessador Z80A e memória, as quais estão inseridas em computador do tipo IBM-PC. Os resultados foram obtidos pelo programa Maestro II da Ortec.

$\mathrm{Na}$ Figura $3 \mathrm{~A}$ é apresentado um espectrograma típico para a calibração do espectrômetro alfa (MCB-1) com padrão de ${ }^{238} \mathrm{U}$ (atividade de $54,6 \mathrm{dpm}$ ) e ${ }^{232} \mathrm{U}-{ }^{228} \mathrm{Th}$ (atividade de $10 \mathrm{dpm}$ ) preparado, no Centre de Faibles Radioactivitès (França), conforme descrito por Bonotto (1986). A figura 3B ilustra o gráfico energia $v s$. canal, que permite relacionar a energia de cada nuclídeo emissor a um diferente canal do aparelho utilizado. Na curva de calibração (Fig. 3B) são assinalados os nuclídeos ${ }^{238} \mathrm{U},{ }^{234} \mathrm{U}$ e ${ }^{228} \mathrm{Th}$ que são aqueles de maior interesse para a determinação dos teores de tório nas amostras. Em virtude de possuírem energia de emissão muito próxima daquela dos jsótopos de tório, os isótopos de urânio assinalados no gráfico de calibração se prestam bem para a localização dos canais de registro das emissões alfa do ${ }^{232} \mathrm{Th},{ }^{230} \mathrm{Th}$ e ${ }^{228} \mathrm{Th}$.

Em geral, a literatura registra baixos valores de concentração de tório em água. Por exemplo, Moore \& Sackett (1964) apresentam resultados de $0,64 \pm 0,20 \mu \mathrm{g} / 1000 \mathrm{l}$ e 4,5 $\pm 0,8 \mu \mathrm{g} /$ $1000 \mathrm{lem}$ água de oceanos. No entanto, é necessário mencionar que alguns autores referem-se a teores de tório em solução sem terem sido efetuadas filtragens das amostras para análise. Por exemplo, o trabalho de Somayajulu \& Goldberg (1966) apresenta valores entre $0,02 \mathrm{e} 0,24 \mu \mathrm{g} / 1000 \mathrm{l}$ para amostras de águas não filtradas. Tal procedimento pode ocasionar discrepância nos resultados, que devem ser considerados com cautela, em virtude de contaminações da fase líquida pelo tório presente em suspensão. Para o caso de estudos realizados na região central do planalto de Poços de Caldas, Lei (1984) obteve resultados entre 0,02 e $0,24 \mu \mathrm{g} / 1$ para o ${ }^{232} \mathrm{Th}$ dissolvido em águas subterrâneas filtradas do Morro do Ferro.

As águas de todas fontes estudadas exibiram fracionamento isotópico entre ${ }^{228} \mathrm{Th}$ e ${ }^{232} \mathrm{Th}$ (Tabela 1), determinando-se, em alguns casos, elevadas razões de atividade entre estes nuclídeos, inclusive valores superiores a 10 . Tal situação também tem sido constatada por outros autores, e. g. Lei (1984) para águas subterrâneas do Morro do Ferro ou Moore (1981) para águas 
(A)

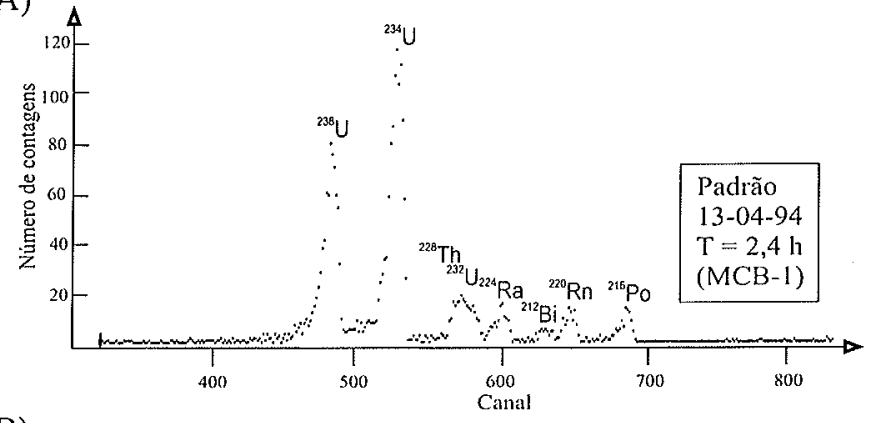

(B)

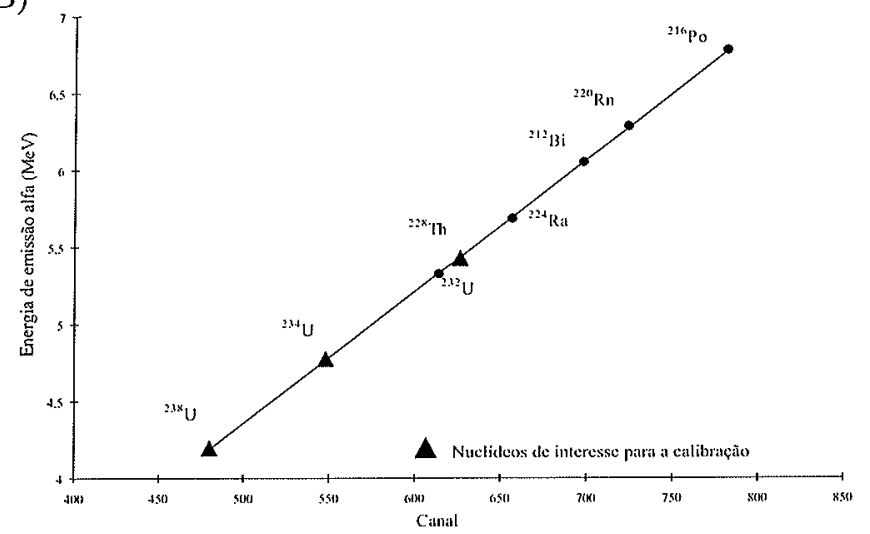

Figura 3 - (A) Espectrograma alfa típico para o padrão de ${ }^{23.8} U-{ }^{2.32} U-{ }^{228} \mathrm{Th}$ que permite a calibração do espectrômetro alfa (T=tempo de contagem); (B) Gráfico de energia vs. canal para a identificação dos canais nos quais são esperados os nuclídeos de interesse.

de oceanos, sendo que, de modo geral, essas razões de atividade tem sido interpretadas considerando-se a possibilidade de mobilização preferencial do ${ }^{228} \mathrm{Ra}$ relativamente ao ${ }^{232} \mathrm{Th}$, causando um enriquecimento de ${ }^{228}$ Th tanto na fração solúvel quanto nos sólidos em suspensão.

As atividades verificadas para ${ }^{230} \mathrm{Th}$ (Tabela 1 ) foram obtidas pela técnica de diluição isotópica (Bonotto 1986 1996), onde o acentuado valor encontrado para a amostra da Fonte Villela (Fig. 4) possivelmente se deve à presença de urânio no material de preenchimento de fendas superficiais no arenito em que as águas são armazenadas (Frayha 1957).

Em virtude de o tório formar complexos inorgânicos em algumas circunstâncias (Langmuir \& Herman 1980), foram realizadas correlações entre os teores de tório dissolvido e os ânions $\mathrm{HPO}_{4}^{2-}, \mathrm{NO}_{3}, \mathrm{SO}_{4}{ }^{2-}, \mathrm{Cl}^{-}$e $\mathrm{F}^{-}$presentes nestas águas (Szikszay 1981, Tonetto 1996, Tonetto \& Bonotto 1997), não tendo sido encontrado qualquer valor significativo.

A figura 5 apresenta os espectrogramas alfa obtidos para o tório extraído dos materiais particulados presentes nas amostras, tendo sido obtidos teores mensuráveis de tório em apenas três delas (Tabela 2). Com exceção da amostra Próx. Platina, notase que os valores para ${ }^{232}$ Th apresentados na Tabela 2 são compatíveis com os obtidos por Lei (1984), que encontrou teores entre 81 e $882 \mu \mathrm{g} . \mathrm{g}^{-1}$ de sólidos suspensos em amostras de águas subterrâneas do Morro do Ferro coletadas no mês de dezembro de 1981.

Os resultados obtidos para as três amostras denotam que é acentuada a mobilização do tório nessa fase, podendo estar ocorrendo adsorvido em materiais orgânicos ou inorgânicos
Tabela 1 - Teores de tório dissolvido e razão de atividade ${ }^{228} \mathrm{Th} /$ ${ }^{232}$ Th nas águas subterrâneas de Águas da Prata (SP). Todas as incertezas analíticas correspondem a $\pm 10 \%$ (desvio padrão de $1 \sigma)$.

\begin{tabular}{|c|c|c|c|c|}
\hline Amostra & $\begin{array}{c}\text { Data da } \\
\text { Coleta }\end{array}$ & $\begin{array}{c}{ }^{232} \mathrm{Th} \\
\left(\mu \mathrm{g} \mathrm{I}^{-1}\right)\end{array}$ & $\begin{array}{c}{ }^{230} \mathrm{Th} \\
\left(\mathrm{dpm}^{*}\right)\end{array}$ & $\begin{array}{c}\text { R. A.* } \\
{ }^{228} \mathrm{Th} 2^{23} \mathrm{Th}\end{array}$ \\
\hline Platina & $21-06-95$ & 0,11 & 0,70 & 1,77 \\
Paiol & $21-06-95$ & 0,61 & 2,10 & 2,79 \\
Próx. Paiol & $13-04-94$ & 0,24 & 2,39 & 13,00 \\
Prata-Radioativa & $13-04-94$ & 0,11 & 0,85 & 2,74 \\
Prata-Nova & $21-06-95$ & 0,65 & 8,93 & 8,31 \\
Prata-Antiga & $13-04-94$ & 1,72 & 23,45 & 5,85 \\
Villela & $21-06-95$ & 0,003 & 22,49 & 34,47 \\
\hline
\end{tabular}

R. A. = Razão de Atividade

como consideram vários autores (e.g. Langmuir \& Herman 1980). Quando se consideram os valores médios obtidos para o tório dissolvido e nos sólidos em suspensão, respectivamente, $0,49 \mu \mathrm{g} \mathrm{l}^{-1}\left(=0,49 \mu \mathrm{g} \mathrm{kg}^{-1}\right)$ e $1308 \mu \mathrm{g} \mathrm{g}^{-1}$, verifica-se que é possível estimar um fator correspondente a cerca de $3 \times 10^{6}$ para a mobilização preferencial do tório no material particulado em relação ao seu transporte na fase líquida. Utilizando-se os dados expressos por Lei (1984) para amostras de águas subterrâneas coletadas no Morro do Ferro em dezembro de 1981, é possível calcular um fator de cerca de $5 \times 10^{6}$ para a mobilização preferencial do tório nos sólidos em suspensão relativamente à fase líquida, o qual é da mesma ordem de grandeza, porém, quase o dobro daquele encontrado neste trabalho para as águas subterrâneas de Águas da Prata. Apesar das duas áreas situaremse no planalto de Poços de Caldas, é possível explicar a diferença encontrada nos dois fatores calculados a partir do fato de que, no Morro do Ferro, as águas subterrâneas transportam maior quantidade de material em suspensão, implicando, dessa maneira, em mobilização mais acentuada de tório nesta fase em relação à líquida.

Os dados para a razão de atividade natural ${ }^{228} \mathrm{Th} / 2.32 \mathrm{Th}$ das amostras de material particulado também foram maiores que a unidade, indicando maior atividade de ${ }^{228} \mathrm{Th}$ em relação à do ${ }^{232} \mathrm{Th}$, como verificado anteriormente para a fase líquida.

CONCLUSÕES Os resultados obtidos nas análises efetuadas permitiram constatar que apesar de ocorrer em minerais de difícil dissolução, o tório é transferido para a fase líquida, já que foi possível constatar sua presença nas águas subterrâneas de Águas da Prata. Igualmente significativa foi a observação de que ocorre uma acentuada mobilização deste elemento nos sólidos em suspensão, excedendo em até cerca de 3 milhões de vezes seu transporte na fração não retida em membrana Millipore $0,45 \mu \mathrm{m}$. Este fator de transferência é da mesma ordem de grandeza daquele obtido em investigações anteriores envolvendo águas subterrâneas amostradas na região central do planalto de Poços de Caldas, onde se situa o Morro do Ferro, 

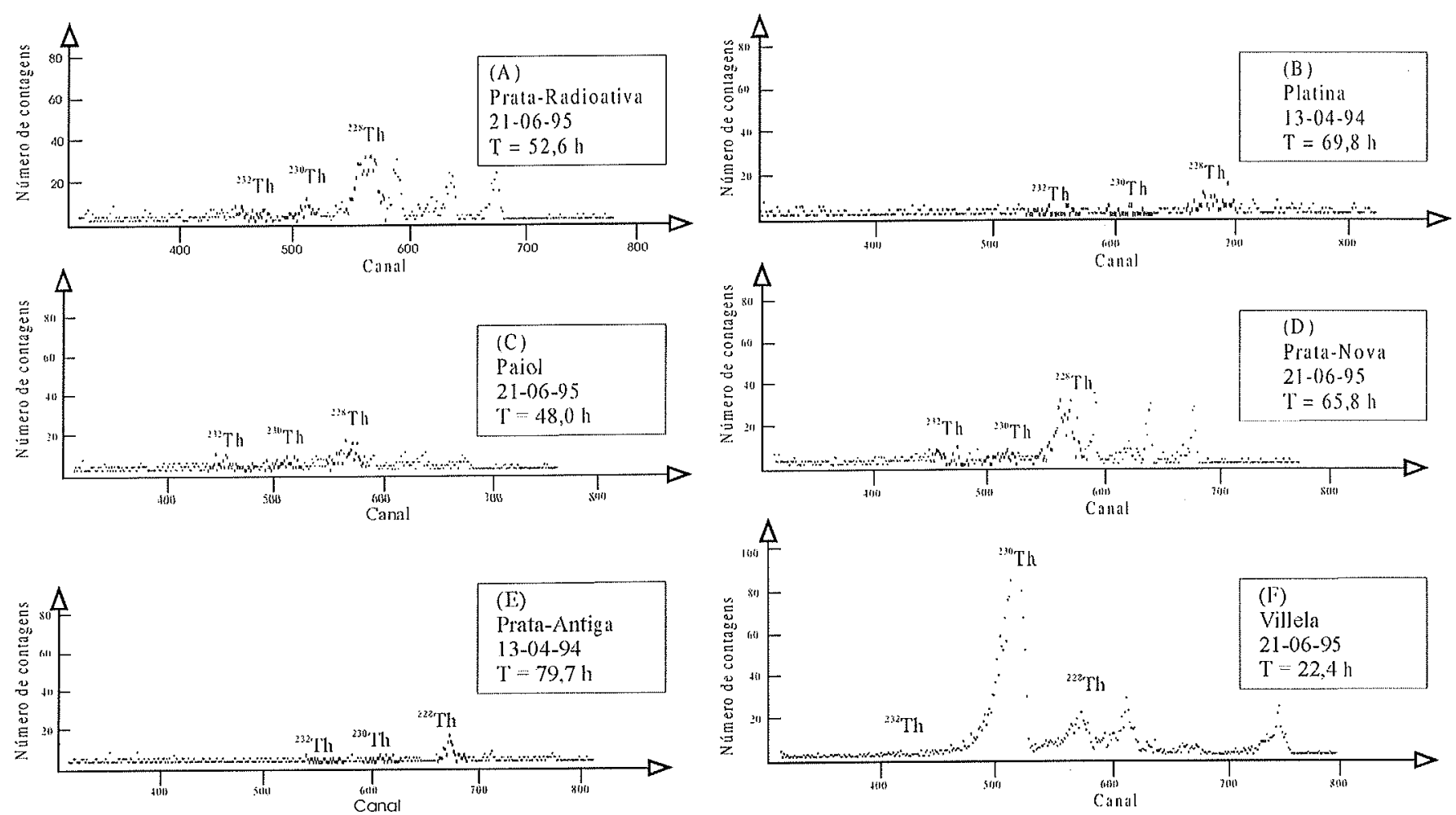

Figura 4 - Espectrogramas alfa obtidos para o tório extraído das amostras de águas subterrâneas de Águas da Prata, processadas quimicamente sem a adição de traçador ${ }^{228} \mathrm{Th}$ ( $T=$ Tempo de contagem; 13-04-94/21-06-95=data da realização da coleta da amostra).

Tabela 2 - Teor de tório e razão de atividade ${ }^{228} \mathrm{Th}^{2.32} \mathrm{Th}$ de materiais em suspensão nas águas subterrâneas de Águas da Prata (SP). Todas as incertezas analíticas correspondem a \pm $10 \%$ (desvio padrão de $1 \sigma$ ).

\begin{tabular}{|c|c|c|c|}
\hline Amostra & Data da Coleta & $\begin{array}{c}{ }^{232} \mathrm{Th} \\
\left(\mu \mathrm{g} \cdot \mathrm{g}^{-1}\right)\end{array}$ & $\begin{array}{c}\text { R. A. } \\
{ }^{228} \mathrm{Th} /{ }^{232} \mathrm{Th}\end{array}$ \\
\hline Próx. Platina & $13-04-94$ & 3445 & 2,58 \\
\hline Vitória & $13-04-94$ & 183 & 11,08 \\
\hline Villela & $13-04-94$ & 297 & 6,45 \\
\hline
\end{tabular}

${ }^{*}$ R. A. = Razão de Atividade.

local de ocorrência de depósito de tório e terras raras. As diferenças encontradas são compatíveis com as litologias das duas áreas, relacionando-se com os processos de interação água/ solo-rocha, que implicam numa transferência não homogênea de material particulado para a fase líquida. Apesar de não ter sido encontrada correlação entre os caracteres químicos e físicoquímicos e as concentrações de tório, as informações geradas fornecem subsídios importantes para o entendimento do comportamento geoquímico desse elemento em solução, qual é complexo, conforme reconhecido inclusive pelos geocronólogos que encontram muita dificuldade na interpretação de idades baseadas no método $\mathrm{Th}-\mathrm{Pb}$, em geral mais discordantes que aquelas obtidas com base em outros elementos/isótopos.
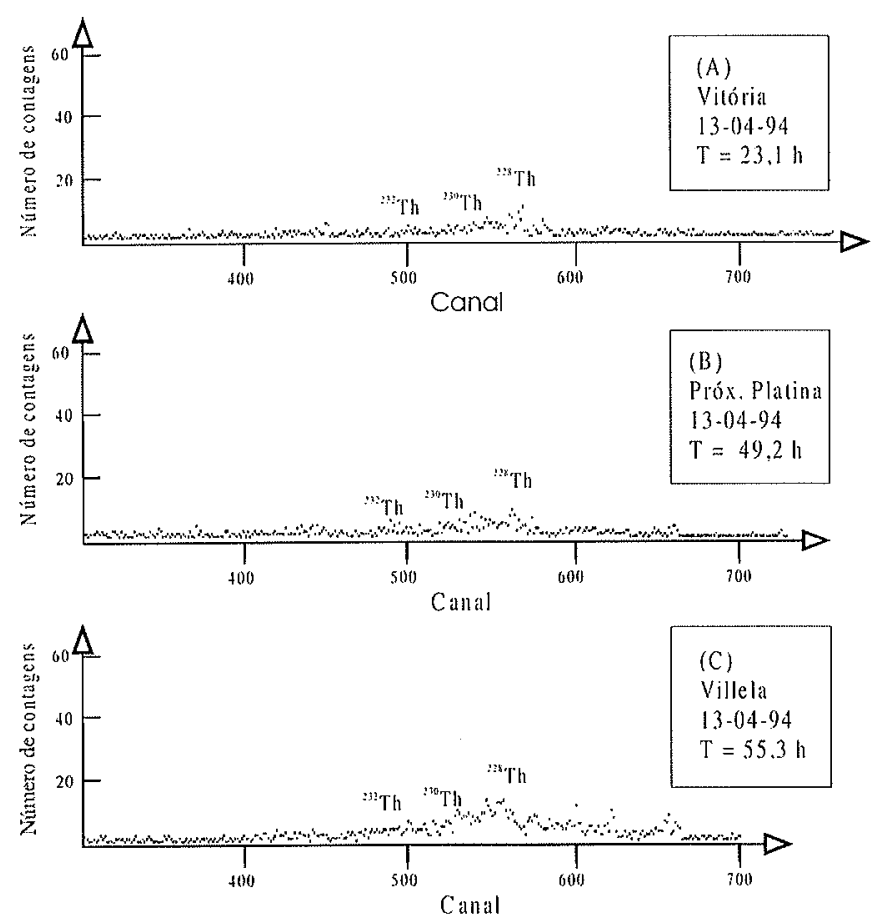

Figura 5-Espectrogramas alfa obtidos para o tório extraído do material em suspensão nas águas subterrâneas de Águas da Prata processadas quimicamante sem adição de traçador ${ }^{228} \mathrm{Th}$ ( $T=$ Tempo de contagem; 13-04-94= data da realização da coleta da amostra). 
Agradecimentos À Fundação de Amparo à Pesquisa do Estado de São Paulo - FAPES (Processo 94/2007-0), à Fundação para o Desenvolvimento da Unesp - FUNDUNESP (Pro- cesso 47-94/CET), ao Conselho Nacional de Desenvolvimento Científico e Tecnológico - CNPq pela bolsa de estudos e aos

\section{Referências}

Anderson P.S., Wasserburg G.J., Chen J.H., Papanastassiou D.A., Ingri J. $1995,{ }^{238} \mathrm{U}-{ }^{234} \mathrm{U}$ and ${ }^{232} \mathrm{Th}-{ }^{230} \mathrm{Th}$ in the Baltic Sea and river water. Earth and Planetary Science Letters, 130:217-234.

Bacon M.P. \& Anderson R.F. 1982. Distribution of thorium isotopes between dissolved and particulate forms in deep sea. J. Geophys. Res., 87:2045-2056.

Barbosa R.A. 1979. Síntese petrográfica do Planalto de Poços de Caldas. Mineração e Metalurgia, 42:38-41.

Björnberg A.J.S. 1959. Rochas clásticas do planalto de Poços de Caldas. Boletim da FFCL - USP, 237 (Geologia n 18): 64-122.

Bonotto D.M. 1982. Aplicação dos dados de fracionamento isotópico 234U/238U nos problemas geoquímicos dos aquíferos de Águas da Prata (SP). Instituto Astronômico e Geofísico, Universidade de São Paulo, São Paulo, Dissertação de Mestrado, 161 p.

Bonotto D.M. 1986. Aplicações hidrogeoquímicas dos isótopos naturais das séries do U (4n+2) e Th (4n) no Morro do Ferro, Poços de Caldas (MG). Instituto Astronômico e Geofísico, Universidade de São Paulo, São Paulo, Tese de Doutorado, 377 p.

Bonotto D.M. 1990. Spikes em espectrometria alfa para análise de amostras geológicas. Geociências, $n^{\circ}$ especial: 251-270.

Bonotto D.M. 1996. Comportamento hidrogeoquímico do ${ }^{222} R n$ e isótopos de urânio ${ }^{238} U$ e ${ }^{234} U$ sob condições controladas de laboratório e em sistemas naturais. Instituto de Geociências e Ciências Exatas, Universidade Estadual Paulista, Rio Claro, Tese de Livre Docência, 223 p.

Chapman N.A., McKinley I.G., Shea M.E., Smellie J.A.T. 1991. The Poços de Caldas Project: summary and implications for radioactive waste management. NAGRA: NTB 90-20, SKB: TR 90-11, UK-DOE: WR 90-042, Poços de Caldas Technical Report Series $15,147 \mathrm{p}$.

Dodson R. W., Forney G. J., Swift E. H. 1936. The extraction of ferric chloride from hydrochloric acid solutions by isopropyl ether: J. Am. Chem. Soc., 58:2573-2577.

Ellert R. 1959. Contribuição à geologia do maciço alcalino de Poços de Caldas. Bol. FFCL USP, 237 (Geologia n 18); 63.

Etchebehere M.L.C. 1990. Modelo de exploração mineral aplicado à pesquisa de fontes termais no planalto de Poços de Caldas $M G$ - SP. Instituto de Geociências e Ciências Exatas, Universidade Estadual Paulista, Rio Claro, Dissertação de Mestrado, 158 p.

Frayha R. 1957. Ocorrências uraníferas no arenito de Águas da Prata, São Paulo, Engenharia, Mineração e Metalurgia, 26 (154): 201 208.

Felicíssimo Jr. J. 1965. Notas sobre a "Fonte Paiol" Águas da Prata, SP. Engenharia, Mineração e Metalurgia, XLI (246):221-224.

Ferronsky V.I. \& Polyakov V.A. 1982. Environmental isotopes in the hydrosphere. John Wiley \& Sons, 466 p.

Gabelman J.W. 1977. Migration of uranium and thorium - exploration siguificance. Tulsa, Amer. Assoc. Petro. Geol. 168 p. (Studies in
Geology $\left.n^{\circ} 3\right)$

Ivanovich M. \& Harmon R.A. 1982. Uranium-series Disequilibrium: Applications to Earth, Marine, and Environmental Sciences. Oxford, Clarendon Press, 571 p.

Langmuir D. \& Herman J.S. 1980. The mobility of thorium in natural waters at low temperatures. Geochimica et Cosmochimica Acta, 44:1753-1766.

Lei W. 1984. Thorium mobilization in a terrestrial environment. Medical Center, New York University, New York, Ph.D.Thesis, $414 \mathrm{p}$.

Lima J.L.N. 1993. Implementação de metodologia para a mensuração de Rn-222 e sua aplicação no estudo da radioatividade das águas de Águas da Prata-SP. Instituto de Geociências e Ciências Exatas, Universidade Estadual Paulista, Rio Claro, Dissertação de Mestrado, $155 \mathrm{p}$.

Lima J.L.N. \& Bonotto D.M. 1996. Etapas analíticas para a mensuração de radônio-222 e uso na avaliação da radioatividade das águas de Águas da Prata (SP). Geochem. Brasil., 10:283295.

Longo O.W. 1967. Águas radioativas no Estado de São Paulo. Revista do Instituto Geográfico e Geológico, 19:27-48

Mero F., Szikszay M., Teissedre J.-M. 1980. Simulação hidrometeorológica da estância de Águas da Prata (SP). Rev. Bras. Geoc., 10:155-166.

Migliorini Jr D., Ruiz C.R., Scalognolatto E.D., Pereira E. 1983. Projeto Boa Vista - Relatório Final - Turma VII. Instituto de Geociências e Ciências Exatas, Universidade Estadual Paulista, Rio Claro, Trabalho de Graduação, 97 p.

Moore W.S. 1981. The thorium isotope content of ocean water. Ear. Plan. Sci. Let., 53:419-426.

Moore W.S. \& Sackett W.M. 1964. Uranium and thorium series inequilibrium in sea water. J. Geophys. Res, 69:5401-5405.

Somayajulu B.L.K. \& Goldberg E.D. 1966. Thorium and uranium isotopes in seawater and sediments. Ear: Plan. Sco. Let., 01:102106.

Szikszay M. 1981. Hidrogeoquímica das fontes de Águas da Prata, Estado de São Paulo. Origem, Classificação e Caracterização. Vol. I. Instituto de Geociências, Universidade de São Paulo, Tese de Livre Docência, 193 p.

Szikszay M. \& Sampa M.H.O. 1982. Variação da radioatividade nas águas de fontes da Estância de Águas da Prata. Boletim IG, 13:2542.

Szikszay M. \& Teissedre J.M. 1977. Fontes da estância de Águas da Prata, estado de São Paulo. Bol. Inst. Geoc., 8:83-96.

Tonetto E.M., Bonotto D.M. 1995. Análises físico-químicas de águas de fontes de Águas da Prata. In: SBG/Núcleo São Paulo, Simp. Geol. Sudeste, IV, Águas de São Pedro, Boletim de Resumos, p. 96.

Tonetto E.M. 1996. O tório em águas subterrâneas de Águas da 
Prata (SP). Instituto de Geociências e Ciências Exatas, Universidade Estadual Paulista, Rio Claro, Dissertação de Mestrado, $80 \mathrm{p}$.

Tonetto E.M. \& Bonotto D.M. 1997. Implementação de metodologias para a análise química de águas e sua aplicação no estudo das águas subterrâneas do município de Águas da Prata (SP) In: SBGq, Cong. Bras. Geoq., VI, Salvador, Anais, I:240-243.
Ulbrich H.H.G. J. \& Gomes C.B. 1981. Alkaline rocks from continental Brazil. Ear: Sci. Rev., 17:135-154.

Manuscrito A-1261

Recebido em 11 de outubro de 2001

Revisão dos autores em 25 de agosto de 2002

Revisão aceita em 30 de agosto de 2002 